\title{
Dynamic consolidation of diamond powder into polycrystalline diamond
}

\author{
David K. Potter and Thomas J. Ahrens \\ Seismological Laboratory 252-21, Califomia Institute of Technology, Pasadena, California 91125
}

(Received 26 February 1987; accepted for publication 2 June 1987)

\begin{abstract}
The formation of a polycrystalline solid compact, by fusing an initially porous aggregate of diamond crystals under dynamic shock pressure (7.5-18 GPa), is shown to depend criticaily on the size of the initial crystals. Porous aggregates of $100-150 \mu \mathrm{m}$ diameter crystals upon shock compaction produced compacts. These exhibited pronounced fracturing of the individual crystals and showed no evidence of fusion. Aggregates consisting of ultrafine crystals $(<5 \mu \mathrm{m})$ also exhibited minimal consolidation. However, samples composed of crystals in the range $4-8 \mu \mathrm{m}$ produced strong fused compacts of polycrystalline diamond. A model calculation indicates that at $10 \mathrm{GPa}$ less than 0.07 mass fraction of the diamond powder can be melted and this molten material is quenched in $0.8 \mathrm{~ns}$ for $8-\mu \mathrm{m}-\mathrm{diam}$ crystals.
\end{abstract}

We describe the conditions under which an initially porous aggregate of diamond single crystals fuses together to form a solid compact under moderate dynamic shock pressure $(7.5-18 \mathrm{GPa})$. Formation of such a fused compact requires at least partial melting along the crystal boundaries and resolidification within the duration of the shocked state (otherwise the sample would disintegrate by tensile fallure when rarefaction waves arrive at the compacted powder ${ }^{1}$ ). Figure 1 shows the proposed temperature and pressure range over which liquid carbon may exist. ${ }^{3-5}$ Experimentally the high melting point of diamond is difficult to achieve. Gold et al. melted a portion of the (100) face of a singlecrystal diamond anvil (at $>12 \mathrm{GPa}$ ) with raciation from a $Q$-switched YAG laser and, more recently, Weathers and Bassett ${ }^{3}$ melted $1 \mu \mathrm{m}$ diamond particles at $30 \mathrm{GPa}$ in a diamond anvil cell using a pulsed YAG laser. Venkatesan $e t$ al. ${ }^{8}$ Steinbeck et al., ${ }^{9}$ and Braunstein et $a l^{2}{ }^{2}$ meited graphite with a pulsed ruby laser at pressures of less than $0.1 \mathrm{GPa}$, and all experiments indicated a melting temperature of about $4300 \mathrm{~K}$. The latter study indicated that the liquid evaporates at about $4700 \mathrm{~K}$.

In the present experiments we shocked initially porous samples of diamond single crystals to induce partial melting. We show that continuum temperature calculations (which imply that shock-induced deformation occurs uniformly) do not, for our experimental conditions, give sufficiently high temperatures, for melting to occur. We sought to establish whether shock compaction induces sufficiently high temperatures to produce melting on grain boundaries.

Previous studies suggest that frictional heating from crystal boundary sliding in diamond ${ }^{10,11}$ or shear band deformation in ceramic materials, ${ }^{12}$ could induce higher temperatures than predicted via continuum calculations. The present experiments were conducted on different sizes of natural and synthetic diamond crystals, since the strength of metal or ceramic compacts is ofter observed to increase with decreasing particle size according to a Hall-Petch relation. ${ }^{13,14}$ Also, the model of Schwartz et al. ${ }^{15}$ of shock-wave consolidation of metal powders predicts that, as the particle diameter $d$ is reduced, the properties of the compact are preserved provided the characteristic times in the shock-consolidation process are scaled with $d^{2}$.
Shock compaction was performed using flyer piate impact and a momentum trapping recovery system (see inset, Fig. 1) ${ }^{16,17}$ Stainless-steel flyer plates (16 mm in diameter and $2.5 \mathrm{~mm}$ thick) with velocities of 1.8 to $2.0 \mathrm{~km} / \mathrm{s}$ were impacted against stainless-steel dish-shaped capsules (inner diameter $7 \mathrm{~mm}$, thickness $3 \mathrm{~mm}$ ) containing the diamond crystals. These induced shock pulses with $\sim 0.8 \mu$ durations. A 0.5-mm-thick disk (single crystal) of $\mathrm{Al}_{2} \mathrm{O}_{3}$ was placed between the stainless steel and the diamond crystals so as to prevent metal interacting with the diamond.

Scanning electron microscopy (SEM) of the 100-150 $\mu \mathrm{m}$ natural diamond crystais from shots 885 and 888 (Table I) revealed that the samples were compacted and their bulk density was very high ( $\sim 95-99 \%$ of the crystal density), as indicated by a lack of voids between grains, although a high

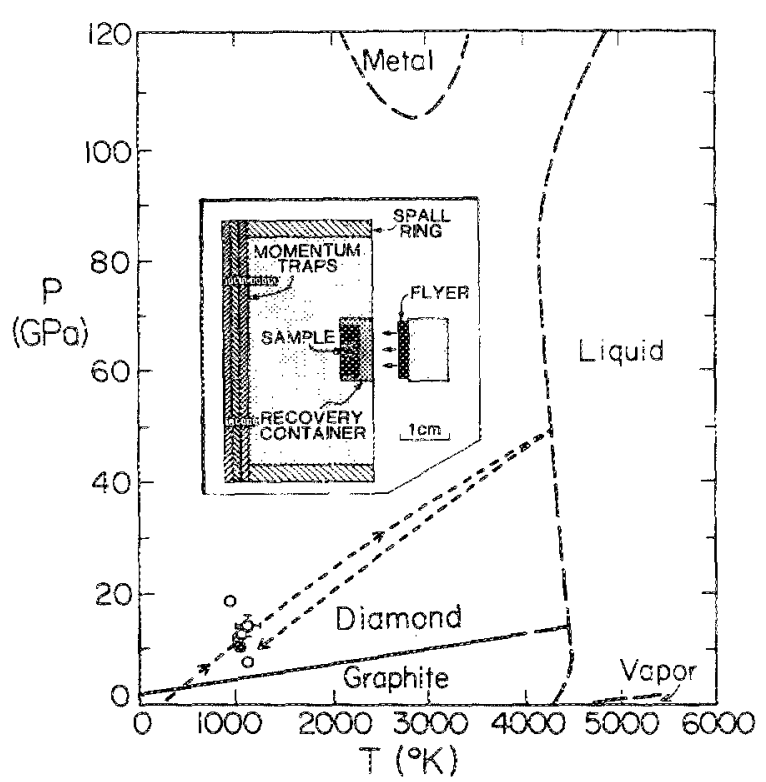

FIG. 1. Shock pressures and continuum temperatures (Table 1 ) and proposed phase diagram of carbon. ${ }^{2-5}$ Solid and open symbols indicate fused and unfused compact continum shock temperatures. Proposed thermodynarric path at grain boundaries indicated by short dashed curve. Diamonddiamond impacts producing higher pressures and temperatures than continuum values. Inset shows sketch of experimental assembly. 
TABLE 1. Experimental conditions and calcubated shock pressures and temperatures.

\begin{tabular}{|c|c|c|c|c|c|c|}
\hline $\begin{array}{l}\text { Shot } \\
\text { number }\end{array}$ & $\begin{array}{l}\text { Initial } \\
\text { sample }\end{array}$ & $\begin{array}{l}\text { Initial } \\
\text { density } \\
\text { (\%o of crystal } \\
\text { density) }\end{array}$ & $\begin{array}{l}\text { Projectile } \\
\text { velocity } \\
(\mathrm{km} / \mathrm{s})\end{array}$ & $\begin{array}{l}\text { Shok }^{*} \\
\text { pressure } \\
\text { (GPa) }\end{array}$ & $\begin{array}{l}\text { Shock } \\
\text { temperature } \\
\text { (K) }\end{array}$ & $\begin{array}{l}\text { Recovered } \\
\text { saniple } \\
\text { condition }\end{array}$ \\
\hline 885 & $\begin{array}{l}\text { noo- } 50 \mathrm{fim} \\
\text { natural } \\
\text { diamond }\end{array}$ & 68 & 1.90 & 18.2 & 920 & $\begin{array}{l}\text { compacted, } \\
\text { no fusion }\end{array}$ \\
\hline 888 & $\begin{array}{l}100-150 \mu \mathrm{m} \\
\text { natural } \\
\text { diamond }\end{array}$ & 55 & $\begin{array}{r}2.01 \\
+0.20\end{array}$ & $\begin{array}{r}14.1 \\
+2.0\end{array}$ & $\begin{array}{r}1140 \\
+\quad 120\end{array}$ & $\begin{array}{l}\text { compacted, } \\
\text { nofusion }\end{array}$ \\
\hline 891 & $\begin{array}{l}48 \mu \mathrm{m} \\
\text { synthetic } \\
\text { diamond } \\
\text { powder }\end{array}$ & 50 & 1.81 & 10.8 & 1040 & $\begin{array}{l}\text { fused } \\
\text { compdet }\end{array}$ \\
\hline 901 & $\begin{array}{l}<5 \mu \mathrm{m} \\
\text { synthetic } \\
\text { diamond } \\
\text { powder }\end{array}$ & 55 & $1.81^{b}$ & 12.0 & 1020 & unconsolidated \\
\hline 904 & $\begin{array}{l}<5 \mu \mathrm{m} \\
\text { synthetic } \\
\text { dianond } \\
\text { powder }\end{array}$ & 38 & 1.81 & 7.5 & 1140 & unconsolidated \\
\hline 907 & $\begin{array}{l}4.8 \mu \mathrm{m} \\
\text { synthetic } \\
\text { diamond } \\
\text { powder }\end{array}$ & 50 & 1.81 & 10.8 & 1040 & $\begin{array}{l}\text { fused } \\
\text { compact }\end{array}$ \\
\hline 910 & $\begin{array}{l}100 \text { pan } \\
\text { symthetic } \\
\text { diamond }\end{array}$ & 55 & 1.86 & 12.7 & 1050 & $\begin{array}{l}\text { compacted. } \\
\text { no fusion }\end{array}$ \\
\hline
\end{tabular}

anitial shock state

${ }^{b}$ Inferred from propellant mass.

degree of fracturing was observed in the individual crystals [Fig. 2(b)]. The 100- $\mu \mathrm{m}$ synthetic diamond crystals (shot 910 ) behaved similarly. There was ro evidence of meling at crystal boundaries in the $100-\mu \mathrm{m}$ natural and synthetic recovered samples. The tensile strength of the compacts was only moderate since it was possible to remove individual grains with a steel probe.

Samples from shots 901 and 904 ( $<5 \mu \mathrm{m}$ synthetic diamond crystals) were observed to be very unconsolidated. Much of the material was loose powder, while more "consolidated" regions were very friable. These latter regions consisted of clumps of individual particles with no evidence of fusion [Fig. 2(d)].

Recovered material formed from 4-8 $\mu \mathrm{m}$ synthetic diamond crystals (shots 891 and 907) revealed clear evidence of fusion between crystals, emphasized by the inability to distinguish original crystal bouncaries in many regions of the SEM images [see region bounded by square in Fig. 2(f) ]. Moreover, the tensile strength of the fused compacts was high as judged by the diffeulty o remove crystals with the steel probe, and by the deposition of steel onto the sample surfaces when scored by the probe. Debye-Scherrer $x$-ray andyses of samples from all experiments demonstrated that no detectable graphite was formed.

Hugoniots for the porous diamond samples were constructed using the shock $\left(U_{s}\right)$ and particle $\left(u_{p}\right)$ velocity data of Pavlovskii for diamond $\left(3.51 \mathrm{Mg} / \mathrm{m}^{3}\right)$,

$$
U_{s}(\mathrm{~km} / \mathrm{s})=12.16+1.00 u_{p},
$$

and Eq. (11.40) of Zeldovich and Raizer ${ }^{19}$ and an assumed Grüneisen parameter $\gamma$ of $0.9 .{ }^{18}$ Shock pressures $\left(P_{Y I}\right)$ were

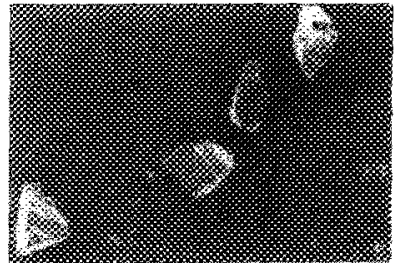

(a) $\longdiv { 1 0 0 \mu \mathrm { m } }$

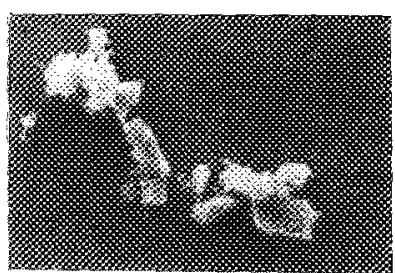

(c)

$$
10 \mu \mathrm{m}
$$

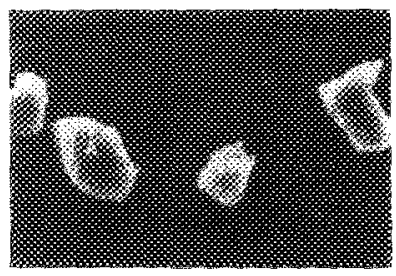

(c)

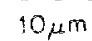

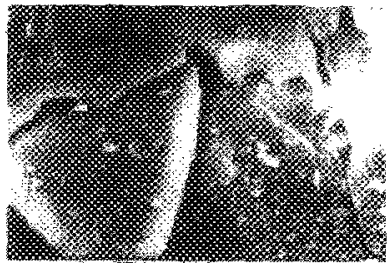

(b)

$10,4 \mathrm{~m}$
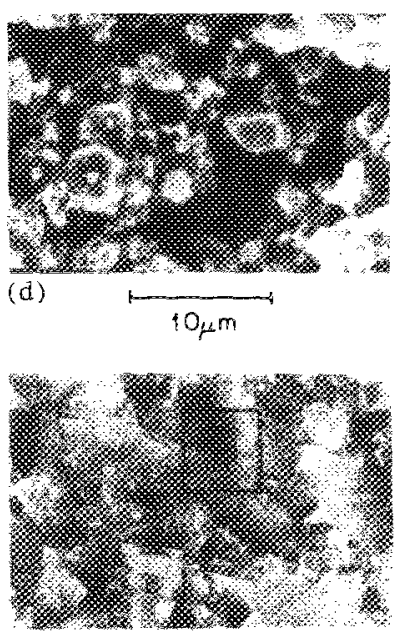

(f)

FlG. 2. SEM images illustraling: (a) $100-150 \mu \mathrm{m}$ natura diamond crystals, unshocked. (b) Fractures produced in shocked $100-150 \mu \mathrm{m}$ natural diamond crystals (shot $\# 888$ ). (c) $<5 \mu \mathrm{m}$ synthetic diamond crystals. unshocked. (d) Unconsolidated sample from shocked $<5 \mu$ m synthetic diamond crystals (shot \#901). (e) 4-8 $\mu \mathrm{m}$ synthetic diamond crystals unshocked. (f) Fused compact formed from $4-8 \mu \mathrm{m}$ synthetic diamond crystals (shot \#891). 
obtained using the impedance matching technique. ${ }^{19}$ The shock (continuum) temperature $T_{H I}$ was calculated from ${ }^{19}$

$$
T_{H}=T_{s}+\frac{V_{H}\left(P_{H}-P_{s}\right)}{\gamma C_{v}}
$$

where $T_{s}$ and $P_{s}$ are the temperature and pressure along the principal isentropes, $V_{H}$ is the high-pressure specific volume, and $C_{v}$ is the specific heat (see pp. 700-701, Ref. 19). Values of $P_{n}$ and $T_{H I}$ are given in Table $I$ and shown in Fig. 1. The continuum temperatures were lower than those predicted for meling, implying that grain sliding friction in duced sufficiently high temperatures at grain boundaries, to cause localized melting, and fuse the powder compacts.

The upper bound for the mass fraction, $L$, of melted material in a typical compacted diamond sample, -0.07 , may be estimated by assuming all the internal energy of the shock goes into melting material on the surface. ${ }^{15,16}$

$$
L=\frac{P_{H}\left[\left(V_{00} / V_{0}\right)-1\right] V_{0}}{2\left[C_{p}\left(T_{m}-T_{0}\right)+H_{m}\right]},
$$

where $P_{I I}$ is taken as $10 \mathrm{GPa}$ and $V_{0}$ and $V_{00}$ are the initial crystal and porous specifie volumes, respectively. Here $V_{00} /$ $V_{0} \approx 1.85$. Also $C_{p}$ is the specific heat at constant pressure, taken ${ }^{20}$ to be $2 \mathrm{~kJ} / \mathrm{kg}^{\circ} \mathrm{C},\left(T_{m}-T_{0}\right)$ is the difference between melting and initial temperature, taken as $4000 \mathrm{~K}$, and the heat of fusion, $H_{m}$, is $9.2 \mathrm{MJ} / \mathrm{kg}$. ${ }^{5}$ We assume that all of the melt is produced as a result of grain friction and coats the individual diamond single crystals.

In order to consolidate the sample material the duration time $t_{d}$ of the shock pulse, $0.8 \mu \mathrm{s}$, must exceed the time $t_{f}$ it takes to conduct the excess heat in the molten carbon layer into the cooler interior of the diamond to freeze the diamonc. In addition, one might also have to wait an additional time $t_{c}$ to cool the hot diamond down to a temperature where it can withstand a moderate arrount of tensile stress associated with unloading. Thus $t_{f}$ is given by ${ }^{15}$

$$
t_{f}=\frac{\pi D}{16}\left(\frac{L d H_{m}}{D C_{p}\left(T_{m}-T_{0}\right)}\right)^{2}
$$

where $D$ is the mean therma! difusivity of the diamond ${ }^{21}$ $\left(1 \times 10^{-4} \mathrm{~m}^{2} / \mathrm{s}\right)$ and $d$ is the crystal diameter. For $d=8 \mu \mathrm{m}$ a freezing time of 0.8 ns is obtained. We note that for the present experiments $t_{d}$ easily exceeds this value. If we assume $\hat{t}_{c}=0$ and put $t_{d}=\hat{t}_{f}=0.8 \mu \mathrm{s}$ we obtain a critical size for $d \sim 250 \mathrm{~km}$, above which fracturing and not consolid: tion may occur. Experimentally we observe fracturing in $100-150 \mu \mathrm{m}$ crystals in agreement with this prediction.

For very small crystals the time constant for thermal equilibrium between the surface and interior $t_{t}\left(\approx d^{2} / D\right)$ ap- proaches the shock transit time $t_{s}\left(=d / U_{s}\right)$ through the crystal. Notably, $t_{s}$ becomes only comparabie with $t_{e}$ at $d=0.1 \mu \mathrm{m}$. Here $t_{s}=0.02 \mathrm{~ns}$ and $t_{e}=0.1 \mathrm{~ns}$. Thus surface melting and fusion, and hence consolidation, are predicted not to take place in ultrafine crystals. Lack of surface fusion is already evident upon compaction of $<5 \mu \mathrm{m}$ powder, which only qualitatively agrees with this prediction.

This work was supported by the National Science Foundation and under the C.I.T. Program for Advanced Technologies (sponsored by GTE, TRW, Aerojet General, and General Motors) contribution number 4443, Division of Geological and Planetary Sciences. We appreciate the help of Dr. John Armstrong, Dr. Tan Kutcheon, and Cheryl Brigham in obtaining the SEM images, and Dr. Liselotte Schioler and an anonymous reviewer for helpful comments on the manuscript.

'W. H. Gourdin, Prog. Mater. Sci. 30, 39 (1986).

${ }^{2} \mathrm{G}$. Braunstein, J. Steinbeck, M. S. Dresselhaus, G. Dressehaus, B. S. Elman, T. Yenkatesan, B. Wikens, and D. C. Jacobsen, Beam Solid Interactions and thase Transiomations: Proceedings of the Materials Resectreh Sociey (Boston), edited by 1 I. Kurz, G. L. Olson, and J. M. Poate, \$1, 233 (1986).

3F. P. Bundy, J. Geophys. Res. 85, 6930 (1980).

${ }^{4} J$. W. Shaner, J. M. Brown, C. A. Swenson, and R. G. McQueen, J. Phys. (Paris) 45, C8-235 (1984).

${ }^{5}$ J. A. Van Vochten, Phys. Rev. B 7, 1479 (1973).

'J. S. Gold, W. A. Bassett, M. S. Weathers, and J. M. Bird, Seience 225,921 (1984).

TM. S. Weathers and W. A. Bassett, Phys Chem. Min. (to be published).

${ }^{8}$ T. Venkatesan, D. C. Jacobsen, J. M. Gibson, B. S. Elman, G. Braunstein, M. S. Dresselhaus, and G. Dressehaus, phys. Rev. Lett. 53,360 (1984).

9. Steinbeck, G. Braunstein, M. S. Dresselhaus, T. Venkatesan, and D. C. Jacobson, J. Appl. Phys. 58, 4374 (1985).

${ }^{10}$ F. P. Bowden and A. E. Hanwell, Nature 281, 1279 (1964).

${ }^{11}$ F. P. Bowden, C. A. Brookes, and A. E. Hanwell, Nature 203, 27 (1964). ${ }^{12}$ D. R. Schmitt and T. J. Ahrens, Geophys. Res. Lett. 10, 1077 (1983).

${ }^{13}$ E. O. Hall, Troc. Fhys. Sow. B 64,747 (1951).

${ }^{14}$ N. J. Petch, J. Iron and Steel Institute 174, 25 (1953).

${ }^{15}$ R. B. Schwarz, $P$. Kasiraj, T. Vreeland, Jr, and T. J. Ahrens, Acta Metall. $32,1243(1984)$

'T.T. J. Ahrens, D. Kostka, P. Kasiraj, T. Vreeland, Jr., A. W. Hare, F. D.

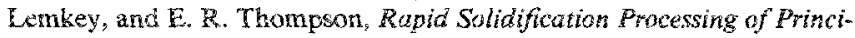
ples and Technologies ZI, edited by R. Mehrabian (National Bureau of Standards, 1983), p. 672 .

7J. Vizgirda, T. J. A hrens, and F.D. Tsay, Geochim. Cosmochim. Acta 22, 1059 (1980).

${ }^{18}$ M. N. Pavlovskii, Sov. Phys. Solid State 13, 741 (1971).

${ }^{19}$ Y. Zeldovich and Y. P. Raizer, Physics of Shock Waves and High Temperatare Hydroilynamic Phenomena, Vol. 2 (Academic, New York, $1967)$.

"'R. A. Robie, B. S. Hemingway, and J. R. Fisher, U. S. Geol. Survey Bull No. $1452,1978$.

2'S. P. Clark, Jr, in Handbook of Physical Constants, edited by S. P. Clark, Jr., Geol. Soc. Am. Mem. 97, 459 (1966). 